\title{
Finisher and performance trends in female and male mountain ultramarathoners by age group
}

This article was published in the following Dove Press journal:

International Journal of General Medicine

19 August 2013

Number of times this article has been viewed

Christoph Alexander Rüst'

Beat Knechtle ${ }^{1,2}$

Evelyn Eichenberger ${ }^{\prime}$

Thomas Rosemann'

Romuald Lepers ${ }^{3}$

'Institute of General Practice and for Health Services Research, University of Zurich, Zurich, ${ }^{2}$ Gesundheitszentrum St Gallen, St Gallen, Switzerland; ${ }^{3}$ French Institute of Health and Medical Research, Faculty of Sport Sciences, University of Burgundy, Dijon, France
Correspondence: Beat Knechtle Facharzt FMH für Allgemeinmedizin, Gesundheitszentrum St Gallen, Vadianstrasse 26, 900 I St Gallen, Switzerland

Tel +4| 07 I 2268282

Tel +4I 07 I 2268272

Email beat.knechtle@hispeed.ch
Background: This study examined changes according to age group in the number of finishers and running times for athletes in female and male mountain ultramarathoners competing in the $78 \mathrm{~km}$ Swiss Alpine Marathon, the largest mountain ultramarathon in Europe and held in high alpine terrain.

Methods: The association between age and performance was investigated using analysis of variance and both single and multilevel regression analyses.

Results: Between 1998 and 2011, a total of 1,781 women and 12,198 men finished the Swiss Alpine Marathon. The number of female finishers increased $\left(r^{2}=0.64, P=0.001\right)$, whereas the number of male finishers $\left(r^{2}=0.18, P=0.15\right)$ showed no change. The annual top ten men became older and slower, whereas the annual top ten women became older but not slower. Regarding the number of finishers in the age groups, the number of female finishers decreased in the age group 18-24 years, whereas the number of finishers increased in the age groups $30-34,40-44,45-49,50-54,55-59,60-64$, and 70-74 years. In the age groups $25-29$ and 35-39 years, the number of finishers showed no changes across the years. In the age group 70-74 years, the increase in number of finishers was linear. For all other age groups, the increase was exponential. For men, the number of finishers decreased in the age groups 18-24, 25-29, $30-34$, and $35-39$ years. In the age groups $40-44,45-49,50-54,55-59,60-64,70-74$, and 75-79 years, the number of finishers increased. In the age group 40-44 years, the increase was linear. For all other age groups, the increase was exponential. Female finishers in the age group 40-44 years became faster over time. For men, finishers in the age groups 18-24, 25-29, 30-34, 40-44, and 45-49 years became slower.

Conclusion: The number of women older than 30 years and men older than 40 years increased in the Swiss Alpine Marathon. Performance improved in women aged 40-44 years but decreased in male runners aged $18-49$ years.

Keywords: ultraendurance, female, male, age group

\section{Introduction}

Participation in marathon ${ }^{1-3}$ and ultramarathon ${ }^{4-7}$ running events has increased since the 1980s. With regard to ultramarathon running, 21 ultramarathons over $161 \mathrm{~km}$ were held in North America in 1998, and the number of annual events increased to 53 per year in $2008 .^{8}$ Through the first half of the 1980s, an increase in participation across the years was observed in $161 \mathrm{~km}$ ultramarathons in the US, but the number of participants has remained stable since $1986 .^{5,6}$ Although the increase in total number of finishers was linear, the number of women participating in ultraendurance running races has increased in recent years. ${ }^{4-6}$ Participation of women increased after the increase in male participation. ${ }^{6}$ The growth of such events was reflected in an increased interest 
in ultraendurance running by the participating female and male athletes. ${ }^{5}$

Performance in ultraendurance events can be affected by a number of factors. It has been shown that physiologic characteristics, ${ }^{9-11}$ anthropometric characteristics, ${ }^{12,13}$ previous experience, ${ }^{14,15}$ training characteristics, ${ }^{13,15}$ age, ${ }^{7,16}$ and gender $^{17}$ are associated with ultraendurance performance. Among these factors, the association between age and endurance performance has been investigated in several studies. ${ }^{7,18,19}$ The decline in endurance ${ }^{20-22}$ and ultraendurance ${ }^{23,24}$ performance with increasing age has been investigated, with ultraendurance performance defined as an endurance exercise of 6 hours in duration or longer. ${ }^{25}$ In ultramarathoners, performance was maintained into a higher age, where the age-related decline was less pronounced than for shorter events. An analysis of male and female $100 \mathrm{~km}$ ultramarathoners found that the fastest running times were achieved at an age of 30-40 years for men and 30-54 years for women. ${ }^{7}$ Similarly, Hoffman reported that the fastest running times in a $161 \mathrm{~km}$ ultramarathon were achieved by athletes aged $35-40$ years. ${ }^{4}$ This is most likely due to the fact that this distance is not attractive for runners in their "prime age" given that the prize money is rather low in ultradistance running. Among the most famous ultramarathons held worldwide, Badwater and Spartathlon are the best known races. ${ }^{26}$ No prize money is offered in Badwater ${ }^{27}$ or Spartathlon. ${ }^{28}$

Ultramarathon running seems to be the domain of master athletes. ${ }^{6,26,29}$ Master runners are defined as runners typically older than 35 years who systematically train for and compete in organized forms of sport usually specifically designed for athletes older than 35 years. ${ }^{30,31}$ Reaburn and Dascombe mentioned that maintaining both a high intensity and a high volume in training could mitigate the age-related decrease in running performance. ${ }^{31}$ However, after the age of 55 years, endurance performance in a number of sports disciplines, including swimming, running, and cycling, decreased in both genders, but was more pronounced in women than men. ${ }^{9,31}$

Increased participation in marathon ${ }^{1-3}$ and ultramarathon $^{4-7}$ running events is due to greater participation by women and by master runners of both genders. ${ }^{4-7,23}$ For marathoners, participation of female master runners has increased to a greater extent than for men, and running times of women older than 44 years and men older than 64 years has decreased significantly over time. ${ }^{2}$ In $100 \mathrm{~km}$ ultramarathoners, the percent of finishers increased significantly for both women and men in the age groups 40-49 years and 50-59 years, where the fastest running times were achieved between 30 and 49 years for men and 30 and 54 years for women, respectively. ${ }^{7}$

Participation and performance trends for master runners have been investigated for marathon ${ }^{1,2}$ and ultramarathon ${ }^{4-7}$ running. In $161 \mathrm{~km}$ mountain ultramarathon races held in the US, running performance improved in women aged 30-39 years. ${ }^{6}$ The demands are different in mountain running compared with flat city marathon running. The hilly trail and the altitude change represent an enormous challenge for runners, both physiologically and psychologically. The question may be raised whether younger athletes should perform better on a hilly trail than older athletes because, with increasing age, body fat increases and skeletal muscle mass decreases, so younger athletes in general should be stronger relative to their weight. ${ }^{31}$ Indeed, from such considerations of general physiologic changes with age, it might be possible that, in a mountain ultramarathon, the age-related decline would be expected to be greater compared with traditional ultramarathons.

In addition, regarding the aspect of gender, women could have an advantage in climbing to high altitude because they have a far lower body weight than men, even though they have more fat and a lower muscle mass. ${ }^{32}$ However, the lower skeletal muscle mass may be a disadvantage for women. ${ }^{32}$ The high altitude in a mountain marathon might also have an influence on the gender difference. Overall faster running times for men could be due to gender differences in physiology. Men have a higher stroke volume because they have a larger heart and therefore a greater cardiac output than women. ${ }^{32}$ Vascularization of skeletal muscle is lower in women due to their lower blood volume. These two factors combined result in a lower oxygen capacity for women. In addition, maximum oxygen uptake is $15 \%-25 \%$ lower in female athletes than in males. ${ }^{32}$

The aim of this study was to examine participation and performance trends according to age group in female and male mountain ultramarathoners competing in the Swiss Alpine Marathon in Europe in high alpine terrain from 1998 to 2011. The Swiss Alpine Marathon started in 1986 as the first mountain ultramarathon in Europe covering $67 \mathrm{~km} .{ }^{33}$ The race now covers a distance of $78 \mathrm{~km}$ and a total altitude change of about 2,260 m. Considering the findings of the Western States 100-Mile Endurance Run in the US, it was hypothesized that participation would increase in both female and male master runners across years, the age of the fastest female and male finishers would increase, and female and male master runners would improve their running times across years. 


\section{Materials and methods}

The dataset from this study was obtained from the race website (www.swissalpine.ch). The race time, gender, and age of all finishers of the Swiss Alpine Marathon were analyzed from 1998 to 2011. All procedures used in the study were approved by the institutional review board of Kanton St Gallen, Switzerland (decision letter, June 1, 2010), with a waiver of the requirement for informed consent of participants, given the fact that the study involved analysis of already publicly available data.

\section{Swiss Alpine Marathon}

The first Swiss Alpine Marathon was held in 1986. From 1986 to 1997 , the course was $67 \mathrm{~km}$ in length and was increased to $78 \mathrm{~km}$ in 1998. The Swiss Alpine Marathon is held annually in July in Davos, Switzerland, and is also known as "K78" because it covers a total distance of $78 \mathrm{~km}$. There is no limit on the number of participants. Figure 1 shows the course of the race with an asphalt (full line), natural trail (broken line), and high alpine trail (dotted line). Athletes have to climb a total altitude change of around 2,260 $\mathrm{m}$. One section crosses $21 \mathrm{~km}$ of high alpine terrain, with a highest altitude of 2,632 $\mathrm{m}$. The athletes start in Davos at 1,538 m above sea level and descend to Filisur, the lowest point in the race, at $1,019 \mathrm{~m}$ above sea level. The runners then climb up to the highest point, ie, the Keschhütte, at 2,632 m above sea level, and turn back to Davos. Over the whole race distance, there are 31 aid stations offering food, water, and hypotonic drinks, and 17 paramedic stations are spread over the running route. The runners have to pass the stations within a time limit. In the event that they fail to pass within the limit, they are withdrawn from the race.

\section{Data analysis}

Complete race results for finishers have been available since 1998. In total, data were available for 13,975 athletes from 1998 to 2011 . To analyze development in participation and performance for the age groups, all finishers were categorized according to age group $(18-24,25-29,30-34,35-39,40-44$, $45-49,50-54,55-59,60-64,65-69,70-74,75-79$, and 80 years and older). Since the number of finishers per year and per age group is highly variable, and some years had not had enough athletes in certain age and gender groups, we investigated the age and running times of the annual top five women (ie, 30-34, 35-39, 40-44, 45-49, and 50-54 years) and men (ie, 25-29, 30-34, 35-39, 40-44, 45-49, 50-54, $55-59,60-64$, and $65-69$ years). Some of the competitors participated for several years and were able to finish several times within the top five.

\section{Statistical analysis}

Data in the text are given as the mean \pm standard deviation. In order to increase the reliability of data analyses, each set of data was tested for normal distribution as well as for homogeneity of variance prior to statistical analysis. Normal distribution was tested using the D'Agostino-Pearson omnibus normality test and homogeneity of variances was tested using the Levene's test. Trends in participation were analyzed using regression analysis with the straight line as well as the exponential growth equation model, whereas for each set of data (eg, each age group), both models were compared using the Akaike Information Criterion to decide which model showed the highest probability of correctness. Single and multilevel regression analyses were used to investigate changes in performance and age of the finishers. A hierarchical regression model was used to avoid the impact of a cluster effect on results in the event that one athlete finished more than once in the annual top ten for the analysis of the annual top ten athletes regarding analysis of overall performance. For the analysis of performance in the age groups, a hierarchical regression model was again used for the top five athletes in each age group. Further, regression analyses of performance were corrected for age of the athletes to prevent misinterpretation of the age effect as a time effect. To identify differences between two groups, a Student's $t$-test was used in the event of normal distribution and a Mann-Whitney test was used in the event of non-normally distributed data.

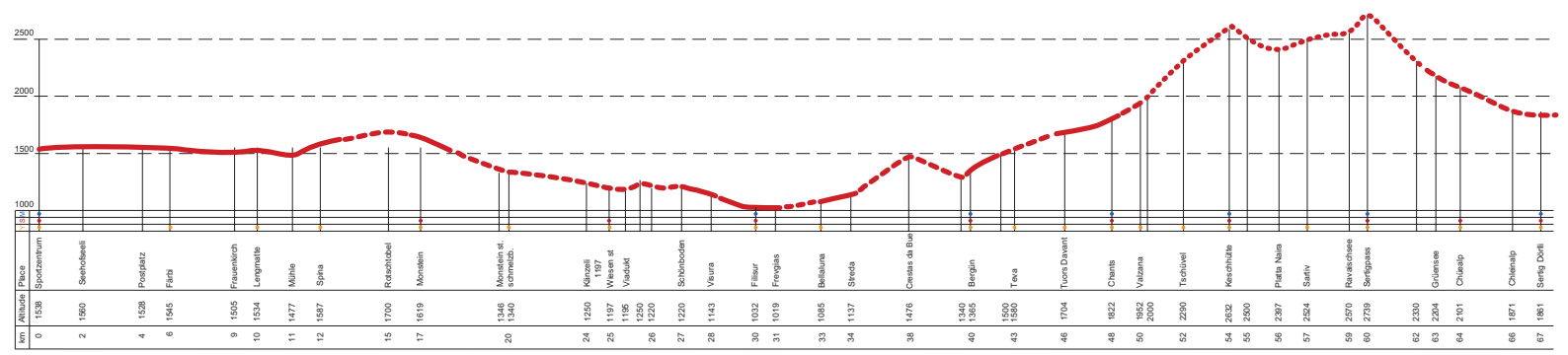

Figure I Profile of the course. 
The performance and age of the annual top ten women and men were tested for interaction between gender and time (ie, year of the competition) using a two-way analysis of variance with gender $\times$ time. Statistical analyses were performed using IBM SPSS Statistics (versions 19 and 21, IBM SPSS, Chicago, IL, USA) and GraphPad Prism (versions 5 and 6.01, GraphPad Software, La Jolla, CA, USA). Significance was accepted at $P<0.05$ (two-sided for $t$-tests).

\section{Results}

\section{Participation trends}

Between 1998 and 2011, a total of 12,198 men and 1,781 women finished the Swiss Alpine Marathon. On average, $127 \pm 48$ women and $871 \pm 134$ men finished the race annually, with a range of 83-251 for women and 738-1,233 for men. Among the male finishers, one athlete finished five times, five athletes finished four times, ten athletes finished three times, and 76 athletes finished twice. All other athletes finished the race once. For women, one athlete finished five times, one athlete finished four times, seven athletes finished three times, and 35 athletes finished two times. All other athletes finished the race once.

Women represented about $12 \%$ of the total field per year. The number of female finishers increased during the study period $\left(r^{2}=0.64 ; P=0.001\right)$, whereas neither the number of male finishers $\left(r^{2}=0.18 ; P=0.15\right)$ nor the number of overall finishers $\left(r^{2}=0.28 ; P=0.06\right)$ showed any changes across the years (Figure 2). The highest number of finishers was in the age group 40-44 years for both women (Figure 3A) and men (Figure 3B).

With regard to age of women finishing this race (Figure 4A), the number of finishers decreased in the age

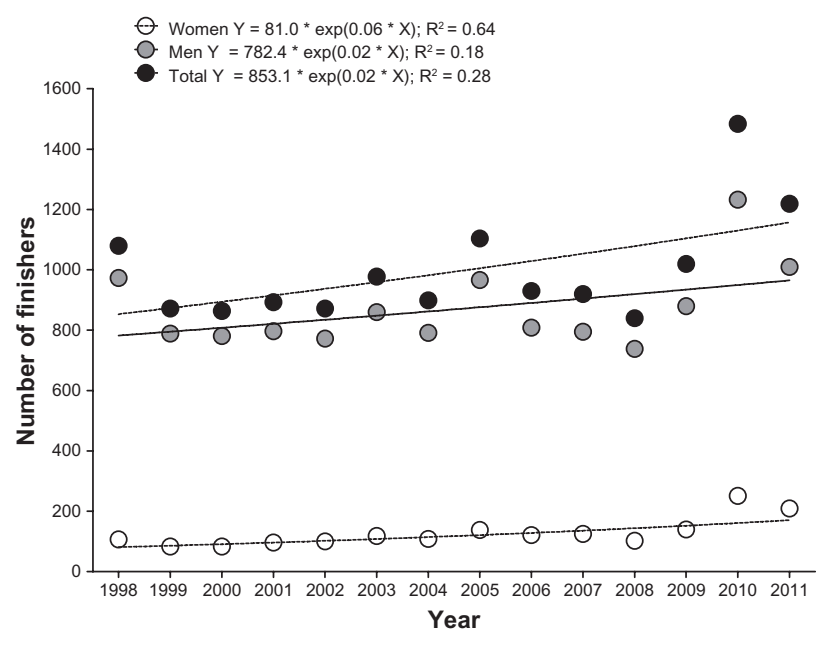

Figure 2 Numbers of female, male, and total finishers at the Swiss Alpine Marathon from 1998 to 2011 . group 18-24 years, whereas the number of finishers increased in the age groups 30-34, 40-44, 45-49, 50-54, 55-59, 60-64, and 70-74 years (Table 1). In the age groups 25-29 and 35-39 years, the number of finishers showed no changes across the years. In the age group 70-74 years, the increase in number of finishers was linear. For all other age groups, the increase was exponential. For men (Figure 4B), the number of finishers decreased in the age groups 18-24, 25-29, 30-34, and 35-39 years (Table 1). In the age groups 40-44, 45-49, 50-54, 55-59, 60-64, 70-74, and 75-79 years, the number of finishers increased. In the age group 40-44 years, the increase was linear. For all other age groups, the increase was exponential.

\section{Performance trends}

Mean race time for the annual top ten finishers was $607.9 \pm 22.7$ minutes for women and $582.7 \pm 18.9$ minutes for men $(P<0.001)$. The gender difference in overall running times was $4.3 \% \pm 1.5 \%$. Regarding overall running times, both women and men became significantly slower across the years. In women, running times increased from $606 \pm 82$ minutes in 1998 to $674 \pm 90$ minutes in $2011\left(r^{2}=0.38 ; P=0.017\right)$. In men, running times increased from $568 \pm 83$ minutes in 1998 to $636 \pm 90$ minutes in $2011\left(r^{2}=0.53 ; P=0.003\right)$. The gender difference in performance remained unchanged across years at $6.7 \% \pm 1.5 \%(P>0.05)$.

For the annual top runners, the mean running time was $354.9 \pm 8.1$ minutes for the annual male winners $(P>0.05)$ and $412.6 \pm 12.2$ minutes for the annual female winners $(P>0.05)$, with a gender difference in performance of $16.0 \% \pm 3.0 \%(P>0.05)$. The top male runners were significantly faster than the top female runners $(P<0.01)$.

For the annual top ten runners, running times in women remained unchanged at $460.4 \pm 13.4$ minutes $\left(r^{2}=0.002\right.$; $P=0.568)$ over time whereas running times in men increased from $372.0 \pm 12.0$ minutes in 1998 to $410.0 \pm 19.0$ minutes in $2011\left(r^{2}=0.19 ; P<0.001\right.$, Figure 5 and Table 2, models 1 and 2). Interaction analysis between gender and time (ie, calendar year) showed no effect on performance $(\mathrm{F}=1.09$; $P=0.36)$. The annual top ten male runners were faster than the annual top ten female runners $(P<0.01)$. The gender difference in running times in the annual top ten decreased from $22 \%$ in 1998 to $17 \%$ in $2011\left(r^{2}=0.29 ; P<0.05\right)$.

Regarding performance in women according to age, only the running times of athletes in the age groups 25-29, 30-34, 35-39, 40-44, 45-49, and 50-54 years could be analyzed (Figure 6A). Faster times across the years were observed for female finishers in the age group 40-44 years (Table 3). 

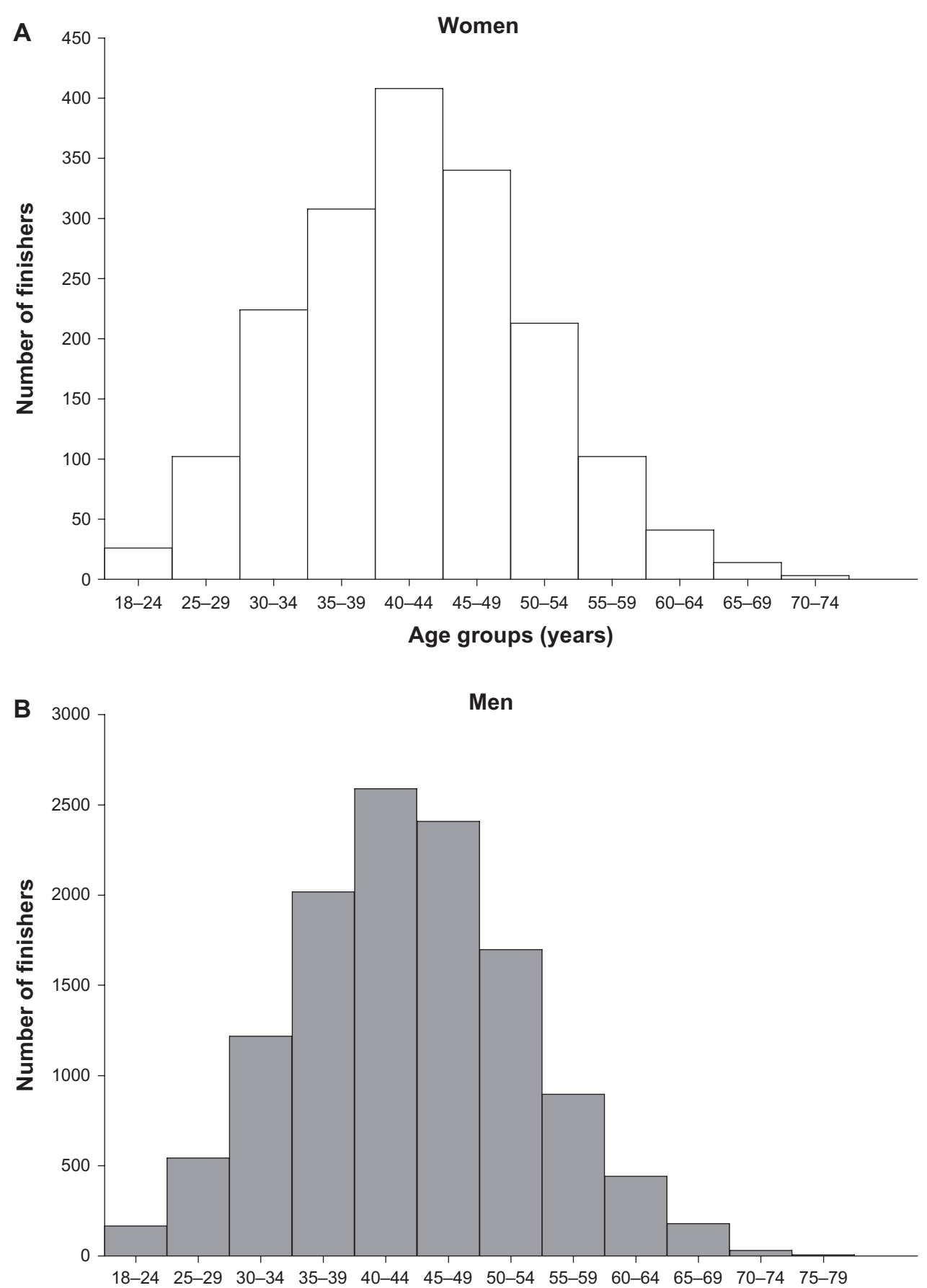

Age groups (years)

Figure 3 Total numbers of finishers by age group for women $(\mathbf{A})$ and men $(\mathbf{B})$ in the Swiss Alpine Marathon.

For men (Figure 6B), athletes in the age groups 18-24, 25-29, 30-34, 40-44, and 45-49 years became slower (Table 4). Statistical analysis showed no change in significance with inclusion of athletes with repeated finishes.

\section{Age trends}

For the annual top ten runners, the age of peak running times increased across the years for both women and men
(Figure 7 and Table 5). For men, the age of peak running time increased from $34 \pm 5$ years in 1998 to $38 \pm 5$ years in $2011\left(r^{2}=0.32 ; P=0.035\right)$, and for women, it increased from $32 \pm 5$ years to $39 \pm 6$ years $\left(r^{2}=0.066 ; P=0.002\right)$. Interaction analysis between gender and time (ie, calendar year) showed no effect on age ( $\mathrm{F}=0.82 ; P=0.63)$. The annual top ten men became older and slower, whereas the annual top ten women became older but not slower. 


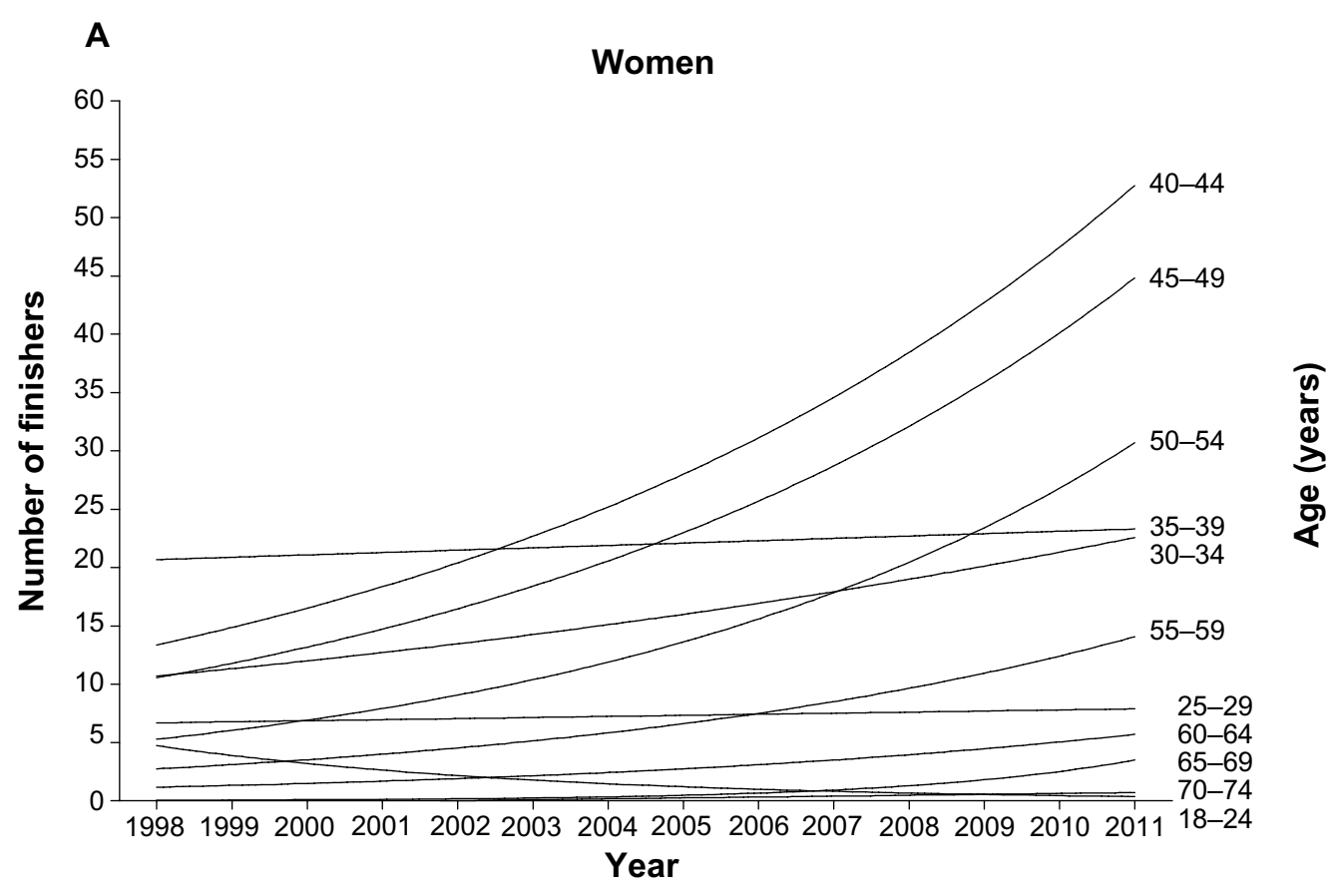

B

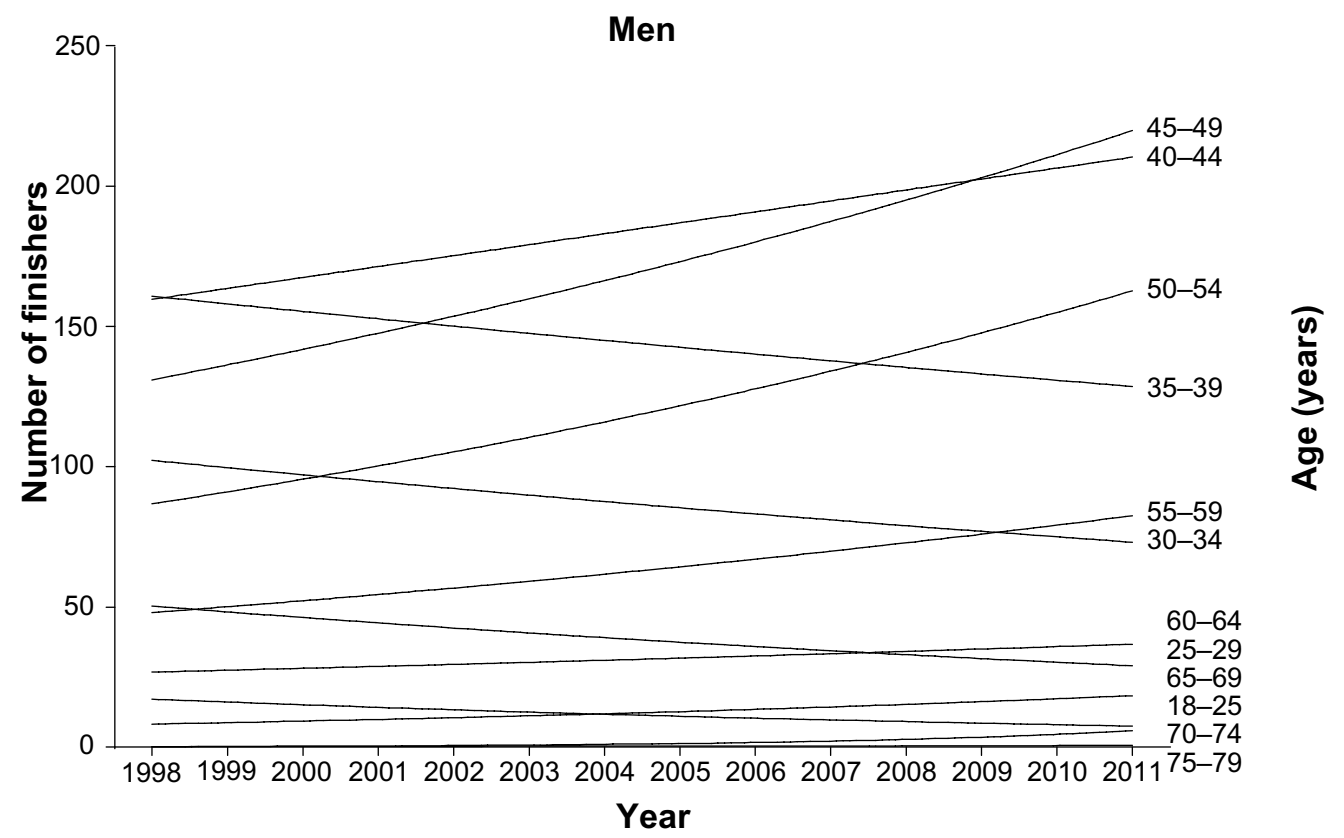

Figure 4 Change in number of finishers by age group for women $(\mathbf{A})$ and men $(\mathbf{B})$ in the Swiss Alpine Marathon across the years.

\section{Discussion}

The aim of this study was to examine participation and performance trends according to age group in female and male mountain ultramarathoners competing in the $78 \mathrm{~km}$ Swiss Alpine Marathon from 1998 to 2011. It was hypothesized for both female and male master runners that participation in terms of number of finishers would increase and performance would improve.

\section{Changes in participation trends}

A main finding was that the number of female overall finishers increased across the years, whereas the number of male overall finishers remained quite stable. Similar findings were reported for $161 \mathrm{~km}$ ultramarathons in the US, where the increase in the total number of finishers became stable. However, the number of women participating in ultraendurance running races has increased in recent years 
Table I Change in number of finishers in age groups over time

\begin{tabular}{|c|c|c|c|}
\hline Age group (years) & YO & $\mathbf{K}$ & $r^{2}$ \\
\hline \multicolumn{4}{|l|}{ Women } \\
\hline $18-24$ & 4.729 & -0.195 & 0.519 \\
\hline $30-34$ & 10.70 & 0.057 & 0.405 \\
\hline $40-44$ & 13.38 & 0.105 & 0.659 \\
\hline $45-49$ & 10.55 & 0.111 & 0.758 \\
\hline $50-54$ & 5.27 & 0.135 & 0.545 \\
\hline $55-59$ & 2.74 & 0.125 & 0.411 \\
\hline $60-64$ & 1.17 & 0.121 & 0.479 \\
\hline \multirow[t]{2}{*}{$65-69$} & 0.04 & 0.33 & 0.376 \\
\hline & $r^{2}$ & $\mathbf{F}$ & $P$ \\
\hline $25-29$ & 0.01 & 0.21 & 0.41 \\
\hline $35-39$ & 0.03 & 0.42 & $0.5 \mathrm{I}$ \\
\hline \multirow[t]{2}{*}{$70-74$} & 0.30 & 5.36 & 0.0047 \\
\hline & YO & $\mathbf{K}$ & $r^{2}$ \\
\hline \multicolumn{4}{|l|}{ Men } \\
\hline $18-24$ & 17.2 & -0.062 & 0.477 \\
\hline $25-29$ & 50.34 & -0.042 & 0.455 \\
\hline $30-34$ & 102.3 & -0.025 & 0.211 \\
\hline $35-39$ & 160.8 & -0.017 & $0.26 \mathrm{I}$ \\
\hline $45-49$ & 131.0 & 0.039 & 0.534 \\
\hline $50-54$ & 86.75 & 0.048 & 0.562 \\
\hline $55-59$ & 48.07 & 0.041 & 0.240 \\
\hline $60-64$ & 26.82 & 0.024 & 0.069 \\
\hline $65-69$ & 8.25 & 0.061 & 0.478 \\
\hline $70-74$ & 0.23 & 0.247 & 0.520 \\
\hline \multirow[t]{2}{*}{$75-79$} & 0.25 & 0.074 & 0.072 \\
\hline & $r^{2}$ & $\mathbf{F}$ & $P$ \\
\hline $40-44$ & 0.27 & 4.62 & 0.046 \\
\hline
\end{tabular}

Notes: For exponential change, $\mathrm{Y}, \mathrm{K}$, and $r^{2}$ are inserted. For linear change, $r^{2}$ $F$, and $P$ are inserted. in the US. ${ }^{4-6}$ The participation rate of women increased after it has increased for men since women started later in these races.

An important finding was that the number of finishers in master athletes increased, while the number of finishers among younger athletes decreased. Therefore, relatively more older than younger athletes were participating. The number of female finishers in the age group 18-24 years decreased, whereas the number of female finishers in the age groups $30-34,40-44,45-49,50-54,55-59,60-64$, and 70-74 years increased. In men, the number of finishers decreased in the age groups $18-24,25-29,30-34$, and 35-39 years, but increased in the age groups $40-44,45-49,50-54,55-59$, 60-64, 70-74, and 75-79 years. A reason for the increased participation of master athletes could be the fact that the general population gets older, and that the expectation of life for the general population increased in the last years. ${ }^{34}$

A further finding was that participation of younger athletes in the age group 18-24 years decreased across the years for both women and men. Also, participation of male athletes decreased in the age group 25-29 years. Similar findings have been reported for $100 \mathrm{~km}$ ultramarathoners. It is likely that younger athletes are attracted by other sports disciplines. There was a high variability from year to year regarding the number of finishers. Different weather conditions might have had an influence on race outcome..$^{17,35}$

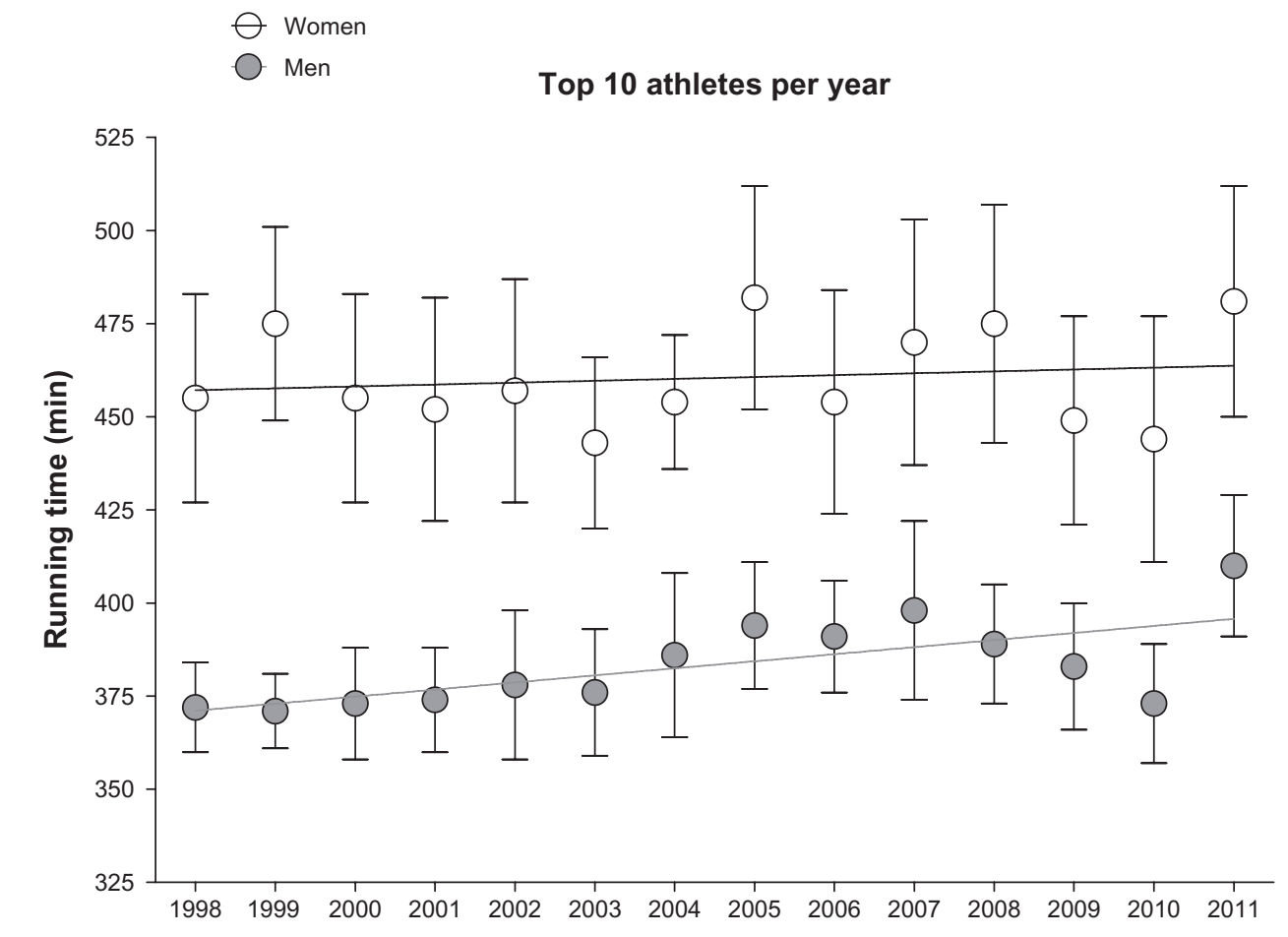

Figure 5 Changes in race time for the annual top ten women and men in the Swiss Alpine Marathon across the years. 
Table 2 Multilevel regression analyses for change in performance across the years for the annual fastest ten women and men (model I), with correction for multiple participations (model 2), and with correction for multiple participation and age of athletes (model 3)

\begin{tabular}{|c|c|c|c|c|c|}
\hline Model & $\beta$ & SE ( $\beta)$ & Standard $\beta$ & $\mathbf{T}$ & $P$ \\
\hline \multicolumn{6}{|c|}{ Annual top ten women } \\
\hline 1 & 0.359 & 0.627 & 0.049 & 0.573 & 0.568 \\
\hline 2 & 0.359 & 0.627 & 0.049 & 0.573 & 0.568 \\
\hline 3 & 0.035 & 0.642 & 0.005 & 0.054 & 0.957 \\
\hline \multicolumn{6}{|c|}{ Annual top ten men } \\
\hline 1 & $2.04 I$ & 0.358 & 0.436 & 5.695 & $<0.001$ \\
\hline 2 & $2.04 I$ & 0.358 & 0.436 & 5.695 & $<0.001$ \\
\hline 3 & 1.889 & 0.358 & 0.404 & 5.274 & $<0.001$ \\
\hline
\end{tabular}

Abbreviation: SE, standard error.

For $161 \mathrm{~km}$ ultramarathoners, age and warmer weather affected race performance depending on gender. Beyond 38 years of age, women had worse odds of finishing than men. Warmer weather had a similar effect on finish rates for men and women. Finish times were slower with advancing age, slower for women than men, and less affected by warm weather for women than for men. ${ }^{35}$
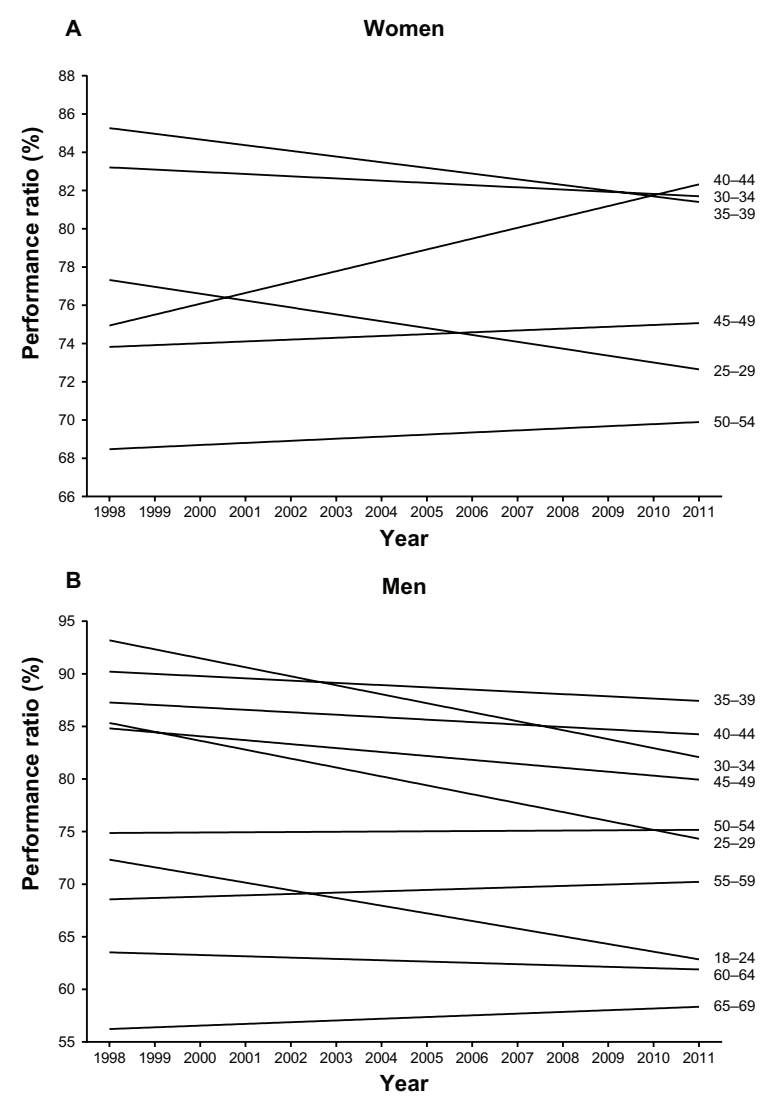

Figure $\mathbf{6}$ Change in performance ratio by age group for women $(\mathbf{A})$ and men $(\mathbf{B})$ in the Swiss Alpine Marathon across the years.
Table 3 Multilevel regression analyses for change in performance across the years for female runners according to age group (model I), with correction for multiple participations (model 2), and with correction for multiple participation and age of athletes (model 3)

\begin{tabular}{lllllll}
\hline $\begin{array}{l}\text { Age group, } \\
\text { years }\end{array}$ & Model & $\beta$ & SE $(\boldsymbol{\beta})$ & Standard $\boldsymbol{\beta}$ & $\mathbf{T}$ & $\boldsymbol{P}$ \\
\hline $25-29$ & $\mathrm{I}$ & -0.333 & 0.241 & -0.172 & -1.383 & 0.172 \\
& 2 & -0.333 & 0.241 & -0.172 & -1.383 & 0.172 \\
& 3 & -0.314 & 0.240 & -0.162 & -1.307 & 0.196 \\
$30-34$ & $\mathrm{I}$ & $-0.27 \mathrm{I}$ & 0.204 & -0.153 & -1.327 & 0.189 \\
& 2 & -0.271 & 0.204 & -0.153 & -1.327 & 0.189 \\
& 3 & -0.284 & 0.204 & -0.161 & -1.394 & 0.168 \\
$35-39$ & $\mathrm{I}$ & -0.071 & 0.182 & -0.045 & -0.388 & 0.699 \\
& 2 & -0.071 & 0.182 & -0.045 & -0.388 & 0.699 \\
& 3 & -0.081 & 0.182 & -0.052 & -0.445 & 0.658 \\
$40-44$ & $\mathrm{I}$ & 0.470 & 0.139 & 0.369 & 3.391 & 0.001 \\
& 2 & 0.470 & 0.139 & 0.369 & 3.391 & 0.001 \\
& 3 & 0.464 & 0.138 & 0.364 & 3.364 & 0.001 \\
$45-49$ & $\mathrm{I}$ & 0.192 & 0.118 & 0.187 & 1.623 & 0.109 \\
& 2 & 0.192 & 0.118 & 0.187 & 1.623 & 0.109 \\
& 3 & 0.212 & 0.112 & 0.206 & 1.895 & 0.062 \\
$50-54$ & $\mathrm{I}$ & 0.113 & 0.117 & 0.112 & 0.966 & 0.337 \\
& 2 & 0.113 & 0.117 & 0.112 & 0.966 & 0.337 \\
& 3 & 0.112 & 0.117 & 0.112 & 0.964 & 0.338 \\
\hline
\end{tabular}

Abbreviation: SE, standard error.

\section{Changes in running times}

The mean race times of $607.9 \pm 22.7$ minutes in women and $582.7 \pm 19.0$ minutes in men for all finishers were close, with a low gender difference in overall running times of $4.3 \% \pm 1.5 \%$. In ultraendurance events, women seem to be able to match the performance of men in specific disciplines, as has been shown for ultraswimming in recent studies. In the English Channel Crossing race, the annual fastest swim speeds did not differ between the genders. ${ }^{36}$ In the $26.4 \mathrm{~km}$ open water Marathon Swim in Lake Zurich, Switzerland, the mean swimming times of the finishers did not differ between women and men, ${ }^{37}$ and in the Zurich 12-h Swim in Switzerland from 1996 to 2010, the annual best performance was not significantly different between women and men. ${ }^{38}$

Overall, men were faster than women. The gender difference in race performance times was approximately $16 \%$ for the annual winners. This gender difference appears to be larger than values reported by Coast et al, who reported that running speed in men was $12.4 \%$ faster than in women for running distances of 100-200 km. ${ }^{39}$ Similarly, Cheuvront et al reported a gender difference of $8 \%-14 \%$ for running distances of $1,500 \mathrm{~m}$ to $42 \mathrm{~km} .{ }^{40}$ The larger gender difference in overall performance in the present mountain ultramarathoners could have been caused by anthropometric 
Table 4 Multilevel regression analyses for change in performance across the years for male age group runners (model I), with correction for multiple participations (model 2), and with correction for multiple participation and age of athletes (model 3 )

\begin{tabular}{|c|c|c|c|c|c|c|}
\hline $\begin{array}{l}\text { Age group, } \\
\text { years }\end{array}$ & Model & $\beta$ & $\begin{array}{l}\text { SE } \\
(\beta)\end{array}$ & $\begin{array}{l}\text { Standard } \\
\beta\end{array}$ & $\mathbf{T}$ & $P$ \\
\hline \multirow[t]{3}{*}{$18-24$} & 1 & -0.484 & 0.193 & -0.282 & -2.509 & 0.014 \\
\hline & 2 & -0.484 & 0.193 & -0.282 & -2.509 & 0.014 \\
\hline & 3 & -0.508 & 0.186 & -0.296 & -2.732 & 0.008 \\
\hline \multirow[t]{3}{*}{$25-29$} & I & -0.701 & 0.150 & -0.481 & -4.685 & $<0.001$ \\
\hline & 2 & -0.701 & 0.150 & $-0.48 I$ & -4.685 & $<0.00 \mathrm{I}$ \\
\hline & 3 & -0.721 & 0.137 & -0.495 & -5.254 & $<0.001$ \\
\hline \multirow[t]{3}{*}{$30-34$} & 1 & -0.923 & 0.145 & -0.597 & -6.358 & $<0.001$ \\
\hline & 2 & -0.923 & 0.145 & -0.597 & -6.358 & $<0.001$ \\
\hline & 3 & -0.910 & 0.136 & -0.588 & -6.692 & $<0.001$ \\
\hline \multirow[t]{3}{*}{$35-39$} & 1 & -0.173 & 0.115 & -0.173 & -1.504 & 0.137 \\
\hline & 2 & -0.173 & 0.115 & -0.173 & -1.504 & 0.137 \\
\hline & 3 & -0.157 & 0.096 & -0.158 & -1.636 & 0.106 \\
\hline \multirow[t]{3}{*}{$40-44$} & I & -0.274 & 0.107 & -0.288 & -2.570 & 0.012 \\
\hline & 2 & -0.274 & 0.107 & -0.288 & -2.570 & 0.012 \\
\hline & 3 & -0.272 & 0.095 & -0.286 & -2.854 & 0.006 \\
\hline \multirow[t]{3}{*}{$45-49$} & 1 & -0.346 & 0.108 & -0.352 & -3.214 & 0.002 \\
\hline & 2 & -0.346 & 0.108 & -0.352 & -3.214 & 0.002 \\
\hline & 3 & -0.354 & 0.097 & -0.361 & -3.658 & 0.000 \\
\hline \multirow[t]{3}{*}{$50-54$} & I & 0.095 & 0.106 & 0.104 & 0.893 & 0.375 \\
\hline & 2 & 0.095 & 0.106 & 0.104 & 0.893 & 0.375 \\
\hline & 3 & 0.116 & 0.098 & 0.128 & 1.181 & $0.24 I$ \\
\hline \multirow[t]{3}{*}{$55-59$} & 1 & 0.147 & 0.089 & 0.189 & 1.647 & 0.104 \\
\hline & 2 & 0.147 & 0.089 & 0.189 & 1.647 & 0.104 \\
\hline & 3 & 0.140 & 0.087 & 0.180 & 1.604 & 0.113 \\
\hline \multirow[t]{3}{*}{$60-64$} & 1 & 0.011 & 0.100 & 0.013 & 0.114 & 0.909 \\
\hline & 2 & 0.011 & 0.100 & 0.013 & 0.114 & 0.909 \\
\hline & 3 & -0.002 & 0.091 & -0.003 & -0.026 & 0.980 \\
\hline \multirow[t]{3}{*}{$65-69$} & I & 0.070 & 0.109 & 0.075 & 0.642 & 0.523 \\
\hline & 2 & 0.070 & 0.109 & 0.075 & 0.642 & 0.523 \\
\hline & 3 & 0.088 & 0.101 & 0.094 & 0.870 & 0.387 \\
\hline
\end{tabular}

Abbreviation: SE, standard error.

differences between women and men, such as the difference in skeletal muscle mass between the genders. Men have a higher skeletal muscle mass, which could be the determining difference because muscle mass and strength are needed to climb to high altitude. ${ }^{32,41}$ It might be also possible that the lower maximum oxygen uptake in female endurance athletes compared with men could be disadvantageous for climbing to high altitudes, as would be necessary in the Swiss Alpine Marathon. ${ }^{42}$ Extreme environmental conditions seem to increase the gender difference in ultramarathon running. In the Marathon des Sables between 2003 and 2012, the gender difference in running speed for the top three athletes decreased from $39.5 \%$ in 2003 to $24.1 \%$ in 2012 , with a mean gender difference of $31.7 \% \pm 2.0 \%{ }^{43}$

Over time, the annual fastest men became significantly slower, whereas the annual fastest women showed stable running times. With regard to performance in athletes according to age group, women in the age group 40-44 years became faster, whereas men in the age groups 18-24, 25-29, 30-34, 40-44, and 45-49 years became slower. Similar findings were reported by Knechtle et al in the $100 \mathrm{~km}$ Lauf Biel from 1998 to 2010, in which the top ten male running times increased and the top ten female running times remained stable. ${ }^{7}$ An explanation could be that the number of competitive male athletes decreased during the study period and the number of recreational runners increased. ${ }^{7}$

\section{Changes in age of finishers}

The age of peak performance increased across the years for both the top ten women and the top ten men. For the top ten men, the age of peak running time increased from 34 years to 38 years, and for women increased from 32 years to 39 years. Following the present definition of master athletes, whereby a master athlete is defined as an athlete older than 35 years and systematically training for and starting in organized forms of sport specifically designed for athletes older than 35 years, ${ }^{31}$ the annual top ten finishers turned over the years to master runners. Similar findings have been reported for Ironman triathletes in Ironman Switzerland between 1995 and 2011, where the age of peak performance remained unchanged for men ( $31 \pm 3$ years) but increased for women from $30 \pm 4$ years in 1995 to $36 \pm 5$ years in $2011 .{ }^{44}$ The age of peak athletic performance in physically active people seems to be around 30 years. ${ }^{45}$ After the age of 35 years, the decline in performance has been reported to be linear until the age of 70 years, but thereafter the decline becomes quadratic. ${ }^{46}$ The age-related performance decline seemed to be slowed in physically active people. ${ }^{47}$

\section{Limitations}

Different variables, such as motivation, experience, pain tolerance, knowledge about pacing, knowledge about nutrition, and individual energy requirements under stress that increase with age in these events, have not been investigated. Some of these variables may compensate for the loss of endurance capacity with age, decrease in heart rate, and lower metabolic recovery occuring with increasing age. Over the years, the number of female finishers increased, but not the number of male finishers. In the annual top ten women, running times remained unchanged whereas the running times in men increased. The gender difference in running times in the top ten 


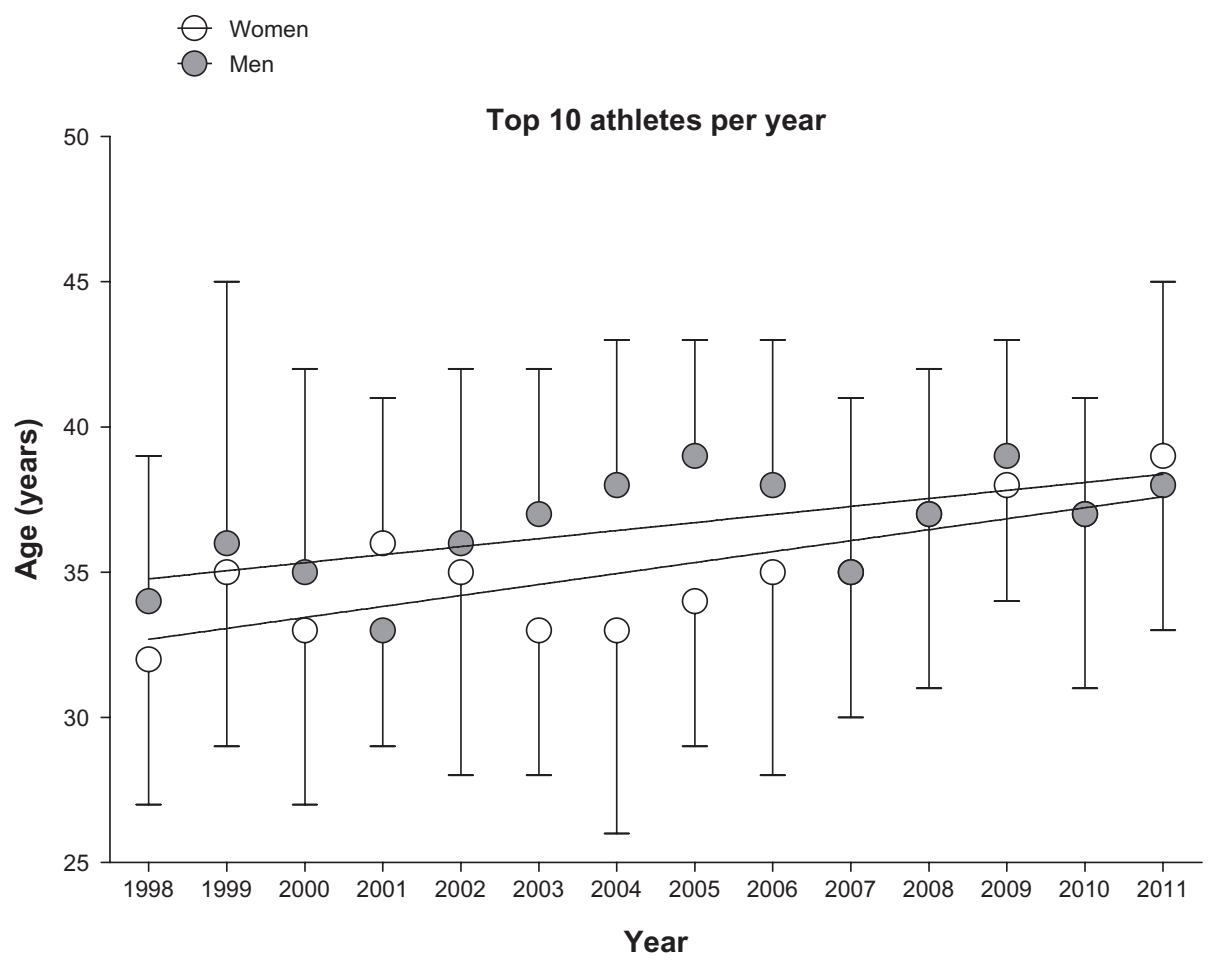

Figure 7 Changes in age of the annual top ten women and men over time in the Swiss Alpine Marathon across the years.

decreased. The lower overall number of female finishers and the variable number of male finishers over the years influences the data analysis. An increase in the number of contestants is not only associated with a better average performance, but also with a lower performance dispersion. ${ }^{48}$ An analysis of running data between 1973 and 2009 revealed that the gender difference in performance considerably narrowed over the years. ${ }^{49}$ This decrease in gender difference was most probably not due to biological differences and/or psychologic predispositions, but rather to changes in sociocultural conditions. Women and men are socialized similarly in many parts of the world, and women are nowadays motivated to train as hard as comparably talented men. ${ }^{49}$

Table 5 Multilevel regression analyses for change in age of the annual top ten women and men (model I) and with correction for multiple participations (model 2)

\begin{tabular}{|c|c|c|c|c|c|}
\hline Model & $\beta$ & SE $(\beta)$ & Standard $\beta$ & $\mathbf{T}$ & $P$ \\
\hline \multicolumn{6}{|c|}{ Annual top ten women } \\
\hline 1 & 0.378 & 0.121 & 0.256 & 3.112 & 0.002 \\
\hline 2 & 0.378 & 0.121 & 0.256 & 3.112 & 0.002 \\
\hline \multicolumn{6}{|c|}{ Annual top ten men } \\
\hline 1 & 0.235 & 0.110 & 0.178 & 2.127 & 0.035 \\
\hline 2 & 0.235 & 0.110 & 0.178 & 2.127 & 0.035 \\
\hline
\end{tabular}

Abbreviation: SE, standard error.

\section{Conclusion}

To summarize, the number of athletes increased in the Swiss Alpine Marathon for women older than 30 years and for men older than 40 years. Female finishers in the age group 40-44 years became faster over time. However, for men, finishers in age group categories became slower across the years. It seemed that female master mountain ultramarathoners have not reached their limits, whereas male master mountain ultramarathoners have definitely reached their limits. Further investigations of anthropometry, physiology, and motivation in mountain ultramarathoners are needed for a better understanding of the gender difference in performance in mountain ultramarathoners and the decrease in performance in male master mountain ultramarathoners. In the future, we might expect a further increase in the number of female master finishers with a continued improvement in performance.

\section{Disclosure}

The authors report no conflicts of interest in this work.

\section{References}

1. Jokl P, Sethi PM, Cooper AJ. Master's performance in the New York City Marathon 1983-1999. Br J Sports Med. 2004;38:408-412.

2. Lepers R, Cattagni T. Do older athletes reach limits in their performance during marathon running? Age (Dordr). 2012;34:773-781. 
3. Leyk D, Erley O, Ridder D, et al. Age-related changes in marathon and half-marathon performances. Int J Sports Med. 2007;28: 513-517.

4. Hoffman MD. Performance trends in $161 \mathrm{~km}$ ultramarathons. Int $J$ Sports Med. 2010;31:31-37.

5. Hoffman MD, Ong JC, Wang G. Historical analysis of participation in $161 \mathrm{~km}$ ultramarathons in North America. Int J Hist Sport. 2010;27: 1877-1891.

6. Hoffman MD, Wegelin JA. The Western States 100-Mile Endurance Run: participation and performance trends. Med Sci Sports Exerc. 2009;41:2191-2198.

7. Knechtle B, Rüst CA, Rosemann T, Lepers R. Age-related changes in $100 \mathrm{~km}$ ultramarathon running performance. Age (Dordr). 2012;34: 1033-1045.

8. Hoffman MD, Fogard K. Factors related to successful completion of a $161 \mathrm{~km}$ ultramarathon. Int J Sports Physiol Perform. 2011;6: 25-37.

9. Easthope CS, Hausswirth C, Louis J, Lepers R, Vercruyssen F, Brisswalter J. Effects of a trail running competition on muscular performance and efficiency in well-trained young and master athletes. Eur J Appl Physiol. 2010;110:1107-1116.

10. Loftin M, Sothern M, Koss C, et al. Energy expenditure and influence of physiologic factors during marathon running. J Strength Cond Res. 2007;21:1188-1191.

11. Pate RR, Macera CA, Bailey SP, Bartoli WP, Powell KE. Physiological, anthropometric, and training correlates of running economy. Med Sci Sports Exerc. 1992;24:1128-1133.

12. Hoffman MD. Anthropometric characteristics of ultramarathoners. Int J Sports Med. 2008;29:808-811.

13. Knechtle B, Wirth A, Knechtle P, Rosemann T. Training volume and personal best time in marathon, not anthropometric parameters, are associated with performance in male $100 \mathrm{~km}$ ultrarunners. $J$ Strength Cond Res. 2010;24:604-609.

14. Knechtle B, Knechtle P, Rosemann T. Race performance in male mountain ultramarathoners: anthropometry or training? Percept Mot Skills. 2010;110(3 Pt 1):721-735.

15. Knechtle B, Knechtle P, Rosemann T, Lepers R. Personal best marathon time and longest training run, not anthropometry, predict performance in recreational 24-hour ultrarunners. J Strength Cond Res. 2011;25: 2212-2218.

16. Knechtle B, Knechtle P, Rosemann T, Lepers R. Predictor variables for a $100 \mathrm{~km}$ race time in male ultramarathoners. Percept Mot Skills. 2010;111:681-693.

17. Rüst CA, Knechtle B, Knechtle P, et al. Gender difference and age-related changes in performance at the long-distance duathlon. J Strength Cond Res. 2013;27:293-301.

18. Knechtle B, Knechtle P, Rüst CA, Rosemann T, Lepers R. Age, training, and previous experience predict race performance in long-distance inline skaters, not anthropometry. Percept Mot Skills. 2012;114:141-156.

19. Lepers R, Maffiuletti NA. Age and gender interactions in ultraendurance performance: insight from the triathlon. Med Sci Sports Exerc. 2011;43:134-139.

20. Baker AB, Tang YQ. Aging performance for masters records in athletics, swimming, rowing, cycling, triathlon, and weightlifting. Exp Aging Res. 2010;36:453-477.

21. Donato AJ, Tench K, Glueck DH, Seals DR, Eskurza I, Tanaka H. Declines in physiological functional capacity with age: a longitudinal study in peak swimming performance. J Appl Physiol. 2003;94: 764-769.

22. Tanaka H, Seals DR. Age and gender interactions in physiological functional capacity: insight from swimming performance. $J$ Appl Physiol. 1997;82:846-851.

23. Lepers R, Rüst CA, Stapley PJ, Knechtle B. Relative improvements in endurance performance with age: evidence from 25 years of Hawaii Ironman racing. Age (Dordr). 2013;35:953-962
24. Stiefel M, Knechtle B, Lepers R. Master triathletes have not reached limits in their Ironman triathlon performance. Scand J Med Sci Sports. May 14, 2012. [Epub ahead of print.]

25. Zaryski C, Smith DJ. Training principles and issues for ultraendurance athletes. Curr Sports Med Rep. 2005;4:165-170.

26. Zingg MA, Knechtle B, Rüst CA, Rosemann T, Lepers R. Analysis of participation and performance in athletes by age group in ultramarathons of more than $200 \mathrm{~km}$ in length. Int J Gen Med. 2013;6:209-220.

27. Badwater. Available from: http://www.badwater.com/2012web/ 2012prepr.html. Accessed April 19, 2013.

28. Spartathlon. Available from: http://www.spartathlon.gr/en/registration/ faqs.htm. Accessed April 19, 2013.

29. Zingg M, Rüst CA, Rosemann T, Lepers R, Knechtle B. Master runners dominate the 24-hour ultramarathons worldwide a retrospective data analysis from 1998 to 2011. Extrem Physiol Med. 2013;2(1):21.

30. Ransdell LB. Vener J, Huberty J. Master athletes: an analysis of running, swimming and cycling performance by age and gender. $J$ Exerc Sci Fit. 2009;7:61-73.

31. Reaburn P, Dascombe B. Endurance performance in masters athletes. Eur Rev Aging Phys Act. 2008;5:31-42.

32. Lynch SL, Hoch AZ. The female runner: gender specifics. Clin Sports Med. 2010;29:477-498.

33. Swiss Alpine Marathon. Available from: http://www.swissalpine.ch. Accessed March 13, 2012.

34. Savidan A, Junker C, Cerny T, Ess S. Premature deaths in Switzerland from 1995-2006: causes and trends. Swiss Med Wkly. 2010;140:w13077.

35. Wegelin JA, Hoffman MD. Variables associated with odds of finishing and finish time in a $161 \mathrm{~km}$ ultramarathon. Eur J Appl Physiol. 2011;111:145-153.

36. Eichenberger E, Knechtle B, Knechtle P, Rüst CA, Rosemann T, Lepers R. Best performances by men and women open-water swimmers during the 'English Channel Swim' from 1900 to 2010. J Sports Sci. 2012;30:1295-1301.

37. Eichenberger E, Knechtle B, Knechtle P, et al. Sex difference in openwater ultra-swim performance in the longest freshwater lake swim in Europe. J Strength Cond Res. 2013;27:1362-1369.

38. Eichenberger E, Knechtle B, Christoph AR, Knechtle P, Lepers R, Rosemann T. No gender difference in peak performance in ultraendurance swimming performance - analysis of the 'Zurich 12-h Swim' from 1996 to 2010. Chin J Physiol. 2012;55:346-351.

39. Coast JR, Blevins JS, Wilson BA. Do gender differences in running performance disappear with distance? Can J Appl Physiol. 2004;29:139-145.

40. Cheuvront SN, Carter R, Deruisseau KC, Moffatt RJ. Running performance differences between men and women: an update. Sports Med. 2005;35:1017-1024

41. Knechtle B, Wirth A, Baumann B, Knechtle P, Rosemann T, Oliver S. Differential correlations between anthropometry, training volume, and performance in male and female Ironman triathletes. $J$ Strength Cond Res. 2010;24:2785-2793.

42. Knechtle B, Müller G, Willmann F, Kotteck K, Eser P, Knecht H. Fat oxidation in men and women endurance athletes in running and cycling. Int J Sports Med. 2004;25:38-44.

43. Knoth C, Knechtle B, Rüst CA, Rosemann T, Lepers R. Participation and performance trends in multistage ultramarathons - the 'Marathon des Sables' 2003-2012. Extrem Physiol Med. 2012;1(1):13.

44. Rüst CA, Knechtle B, Knechtle P, Rosemann T, Lepers R. The age of peak performance in elite male and female Ironman triathletes competing in a qualifier for 'Ironman Hawaii' - 'Ironman Switzerland' from 1995-2011. Open Access J Sports Med. 2012;3:175-182.

45. Fair RC. Estimated age effects in baseball. Journal of Quantitative Analysis in Sports. 2008;4:Article 1.

46. Fair RC. Estimated age effects in athletic events and chess. Exp Aging Res. 2007;33:37-57. 
47. Fair RC. How fast do old men slow down? Rev Econ Stat. 1994;76: 103-118.

48. Frick B. Gender differences in competitive orientations: empirical evidence from ultra-marathon running. $J$ Sports Econom. 2011;12: 317-340.
49. Frick B. Gender differences in competitiveness: empirical evidence from professional distance running. Labour Econ. 2011;18:389-398.

International Journal of General Medicine

Dovepress

\section{Publish your work in this journal}

The International Journal of General Medicine is an international, peer-reviewed open-access journal that focuses on general and internal medicine, pathogenesis, epidemiology, diagnosis, monitoring and treatment protocols. The journal is characterized by the rapid reporting of reviews, original research and clinical studies across all disease areas.

A key focus is the elucidation of disease processes and management protocols resulting in improved outcomes for the patient.The manuscript management system is completely online and includes a very quick and fair peer-review system. Visit http://www.dovepress.com/ testimonials.php to read real quotes from published authors.

Submit your manuscript here: http://www.dovepress.com/international-journal-of-general-medicine-journal 